\title{
Hacia una conceptualización de la educación musical crítica: aplicación de los paradigmas científicos, las teorías curriculares y los modelos didácticos
}

\author{
Towards a conceptualization of critical music education: \\ applications of scientific paradigms, curricular theories \\ and teaching models
}

Pablo Marín-Liébana, José Salvador Blasco Magraner, ${ }^{* *}$ Ana María Botella Nicolás ${ }^{* *}$

Recibido: 15 de septiembre de 2020 Aceptado: 6 de noviembre de 2020 Publicado: 27 de julio de 2021

To cite this article: Marín-Liébana, P., Blasco Magraner, J.S., Botella Nicolás, A. M. (2021). Hacia una conceptualización de la educación musical crítica: aplicación de los paradigmas científicos, las teorías curriculares y los modelos didácticos. Márgenes, Revista de Educación de la Universidad de Málaga. 2 (2), 3-24

DOI: https://doi.org/10.24310/mgnmar.v2i2.10016

\section{RESUMEN}

A lo largo de la historia de la educación se han sucedido diversas revisiones, reformulaciones y cuestionamientos de la misma, que han ido configurando en nuestro imaginario colectivo una idea general de lo que se entiende como educación crítica. En un sentido amplio, pueden incluirse en este proceso tanto las propuestas que emanan del movimiento de la Escuela Nueva, que sitúan al estudiante y sus intereses en el centro del proceso educativo, como el conjunto de tradiciones que se desarrollan a partir de los postulados de la teoría crítica elaborada por la Escuela de Frankfurt, que abordan cuestiones relacionadas con el poder, el diálogo igualitario y el reconocimiento social. No obstante, esta proliferación teórica ha generado una dispersión discursiva que dificulta su comprensión y aplicación en los distintos ámbitos educativos. En el marco de la didáctica general, se ha realizado desde la década de 1980 un esfuerzo por sistematizar estos principios y situarlos en contraposición con otras formas complementarias de entender la educación. Esto se ha llevado a cabo principalmente en base a los conceptos de paradigma científico, teoría curricular y modelo didáctico. Sin embargo, especialmente desde los ámbitos más prácticos, esta sistematización ha sido criticada por ser excesivamente abstracta y poco operativa en relación con las distintas áreas de conocimiento. En este sentido, el objetivo de este artículo es el de formular su aplicación en la conceptualización de una educación musical crítica. Para ello, se ha implementado una revisión bibliográfica en la que se han analizado 97 trabajos. Así, se establecen los parámetros paradigmáticos, curriculares y didácticos que deberían guiar dicha educación musical crítica y se plantean ejemplos que se derivan de ellos como el cuestionamiento de la belleza intrínseca del propio objeto musical, la selección del repertorio utilizado o el reconocimiento a las identidades culturales presentes en el aula.

Palabras clave: teoría crítica; pedagogía crítica; educación musical; teoría de la educación

*Pablo Marín-Liébana

0000-0003-2326-1695

Universitat de València (España)

pablo.marin-liebana@uv.es
**José Salvador Blasco Magraner

0000-0001-8937-5842

Universitat de València (España)

j.salvador.blasco@uv.es
***Ana María Botella Nicolás

0000-0001-5324-7152

Universitat de València (España)

ana.maria.botella@uv.es 


\section{ABSTRACT}

Throughout the history of education, there have been several revisions, reformulations and questioning of it, which have shaped in our collective imagination a general idea of what is understood as critical education. In a broad sense, both the proposals emanating from the New School movement, which place the student and their interests at the center of the educational process, and the set of traditions that have been developed from the postulates of the critical theory built by the Frankfurt School, which deal with issues related to power, equal dialogue and social recognition. However, this theoretical proliferation has generated a discursive dispersion that hinders its understanding and application in different educational fields. Within the framework of general teaching, an effort has been made since the 1980s to systematize these principles and place them in contrast with other complementary ways of understanding education. This has been carried out mainly based on the concepts of scientific paradigm, curriculum theory and teaching model. However, especially from the most practical areas, this systematization has been criticized for being excessively abstract and not very operative in relation to the different fields of knowledge. In this sense, the goal of this article is to state its application in the conceptualization of a critical musical education. For this, a literature review of 97 works has been implemented. Thus, the paradigmatic, curricular and didactic parameters that should lead to a critical musical education are established and examples that arise from them are raised, such as the questioning of the intrinsic beauty of the musical object itself, the selection of the repertoire or the recognition of cultural identities present in the classroom.

Keywords: critical theory; critical pedagogy; music education; education theory

\section{INTRODUCCIÓN}

Cualquier aproximación a la pedagogía crítica con el objetivo de identificar en ella una génesis histórica, unos principios ordenadores y coherentes, y unos fines bien definidos y delimitados, rápidamente toma conciencia de su naturaleza plural y poliédrica. Efectivamente, no se trata de un referente consolidado al que adscribir o no un determinado conjunto de prácticas (Carbonell, 2015; Cascante y Martínez, 2013), ni tampoco se puede otorgar a nadie su autoría, sino que es necesario recurrir a los fundamentos epistemológicos, sociológicos y filosóficos en los que se basa para desvelar su significado e intencionalidades (P. Gimeno, 2013). No obstante, dentro de esta indefinición, diversos autores proponen distintos modelos explicativos sobre sus líneas evolutivas y sus principales manifestaciones.

Por un lado, algunos hacen valer un sentido amplio del concepto de crítica y plantean una genealogía que se inicia con las reformas de la Escuela Nueva, enraizadas en los planteamientos rousseaunianos; transita las perspectivas anarquistas y marxistas, así como la teoría crítica de la sociedad; y desemboca en la dualidad que asigna a la educación una función reproductora y/o transformadora, y en diversos modelos de resistencia (Aubert, Duque, Fisas, y Valls, 2010; Ayuste, Flecha, López, y Lleras, 2003). Por otro lado, P. Gimeno (1995) sitúa el desarrollo ideológico de la Pedagogía Crítica en dicha teoría crítica de la sociedad, elaborada por La Escuela de Frankfurt, y centra su atención en las concreciones que tuvieron lugar durante el siglo XX en el contexto germánico. En tercer lugar, parece existir un consenso más o menos generalizado entre algunos teóricos a la hora de señalar a Paulo Freire como un punto de inflexión determinante en la evolución y cristalización del discurso en torno a la Pedagogía Crítica (Allen y Torres, 2003; Freire, 2009; Mayo, 2008; Nayive y León, 2005). 
Esta diversidad de teorizaciones y tradiciones ha recibido un tratamiento sistematizado en el ámbito de la didáctica general. En este sentido, algunos autores han utilizado y desarrollado los conceptos de paradigma científico (De Miguel, 1988; Guba y Lincoln, 1994; Herrán, 2005; Pérez, 1990; Popkewitz, 1988; Sabariego, 2004; Sáez, 1989; Sánchez-Santamaría, 2013), teoría curricular (Carr y Kemmis, 1988; De la Torre, 1993; Delgado, 1994; Escudero y González, 1984; R. García y Parra, 2010; Popkewitz, 1980; M. Rodríguez, 2002a; Sáez, 1989) y modelo didáctico (Escudero, 1981; F. J. García, 2014; J. Gimeno, 1981; Hernández y Guárate, 2017; Jorquera, 2010; Medina, 2002; Pont, 2002; M. Rodríguez, 1997, 2002b) para definir los diferentes tipos de enfoques existentes en la educación, entre los que se encuentra el crítico. En un primer acercamiento a estos parámetros, a pesar de no tratarse de conceptos unívocos sino de complejas construcciones históricas que en ocasiones se emplean como sinónimos, se podría esbozar que los paradigmas son marcos referenciales que condensan una postura ontológica, epistemológica y metodológica concreta, generalmente en el ámbito de la investigación científica; las teorías, textos que explican, describen o comprenden la realidad; y los modelos, simulaciones simplificadas de la misma. No obstante, la comprensión de las implicaciones educativas de estos términos exige un tratamiento en profundidad de los mismos.

Por otra parte, esta parametrización de tipo generalista presenta un nivel de abstracción que no siempre facilita una comprensión aplicable en las prácticas educativas de las didácticas específicas. Es en este punto donde se sitúa el presente trabajo, cuyo objetivo es utilizar estos tres parámetros para, desde una progresión que va de lo más general, como es la propia concepción de la realidad, a lo más particular, como son las relaciones educativas concretas, definir de forma sistemática una educación musical crítica. Así, se relacionan los paradigmas científicos con cuestiones de la filosofía de la música provenientes de corrientes como la nueva musicología (Citron, 2000; Goehr, 1994, 2002; Talbot, 2002; Wolff, 1996) y la etnomusicología (Cámara, 2004; Nettl, 2015; Rice, 2013); las teorías curriculares con tradiciones educativas actuales que defienden el reconocimiento cultural (Lind y McKoy, 2016), la participación crítica de los estudiantes (Abrahams, 2005; Gowan, 2016) o la contribución de la educación a la justicia social (Benedict, Schmidt, Spruce, y Woodford, 2015; Gould, Countryman, Morton, y Rose, 2009); y los modelos didácticos con clasificaciones específicas de las interacciones que en educación musical tienen lugar en el nivel del aula (Aróstegui, 2014; Jorquera, 2010). De esta manera, se pretende proporcionar un marco teórico adaptado a este ámbito educativo concreto, de forma que docentes e investigadores encuentren en él una referencia para guiar sus prácticas profesionales.

\section{METODOLOGÍA}

Para cumplir con el objetivo de formular una definición sistemática de la educación musical crítica a partir de los conceptos de paradigma científico, teoría curricular y modelo didáctico, se ha llevado a cabo una revisión bibliográfica de tipo narrativo en la que se ha relacionado la literatura proveniente de la didáctica general con aquella específica del ámbito de la música y la educación musical. Con respecto a la primera, se utilizaron como punto de partida diferentes manuales que organizan la educación en base a paradigmas, teorías y modelos y, a partir de ellos, se accedió otros documentos que teorizan sobre la construcción histórica de cada uno de estos conceptos. En cuanto a la literatura relativa a la educación musical, se realizó una prime- 
ra búsqueda de información en las bases de datos Web of Science y Scopus, en la que se utilizó una sintaxis basada en los términos music education y critical pedagogy, localizando 117 artículos científicos. De estos, tras descartar los duplicados, se obtuvo un total de 81 textos. A partir de su lectura, se identificaron diferentes tradiciones teóricas que encajaban con los presupuestos de la pedagogía crítica y, mediante la técnica de snowball, se accedió a los trabajos que contaban con un mayor número de referencias o los que trataban de forma específica la sistematización que aquí se aborda. En total, la muestra estudiada ascendió a 97 trabajos diferentes.

\section{RESULTADOS}

A continuación, se muestran los resultados obtenidos tras la revisión bibliográfica. Estos quedan organizados en torno a los tres parámetros que aquí se estudian, esto es, paradigmas científicos, teorías curriculares y modelos didácticos. En cada apartado se explica cada uno de estos conceptos, se expone su aplicación en el ámbito de la didáctica general y se proyectan sus características sobre la música y la educación musical.

\subsection{Paradigmas científicos}

El concepto de paradigma fue acuñado por el físico, historiador y filósofo de la ciencia Thomas Kuhn en su conocida obra La estructura de las revoluciones científicas (1975), publicada en 1962, quien los definió como "realizaciones científicas universalmente reconocidas que, durante cierto tiempo, proporcionan modelos de problemas y soluciones a una comunidad científica" (Kuhn, 1975, p. 13). En última instancia, se trata de un conjunto de creencias sobre el mundo no verificables, es decir, de una construcción humana no demostrable que solo es defendida a través de la argumentación (Guba y Lincoln, 1994; Marín, 2011). Además, este queda definido través de tres dimensiones distintas que constituyen tres preguntas metafísicas fundamentales (Guba y Lincoln, 1994; Lincoln y Guba, 1984; Sánchez-Santamaría, 2013). La primera es la ontológica, que da respuesta a la forma y naturaleza de la realidad, esto es, a cómo o qué es esta. La segunda es la epistemológica, que responde a la cuestión sobre qué podemos conocer de dicha realidad, es decir, a las relaciones entre el sujeto cognoscente y aquello que puede ser conocido. Por último, la dimensión metodológica se pregunta sobre las posibles maneras de llegar a conocer aquella parte de la realidad que es susceptible de ser conocida.

Esta aportación fue un factor decisivo para el movimiento crítico con la investigación clásica y tradicional que tuvo lugar a partir de la década de 1960 (Sáez, 1989), y dio como resultado que dos décadas más tarde, el debate sobre el estatuto epistemológico de las ciencias sociales se convirtiera en un diálogo en el que tenían cabida fundamentalmente tres paradigmas distintos: el positivista, el hermenéutico y la teoría crítica de la sociedad (Rubio, 1984). En la tabla 1 se muestra una síntesis de las características de cada uno de ellos a partir de las aportaciones de diversos autores (De Miguel, 1988; Guba y Lincoln, 1994; Herrán, 2005; Pérez, 1990; Popkewitz, 1988; Sabariego, 2004; Sáez, 1989; Sánchez-Santamaría, 2013).

De forma resumida, el paradigma positivista considera a la realidad objetiva y, por tanto, su conocimiento es universal y neutro. Busca explicarla, controlarla y predecirla a través de un tipo 


\section{ESTUDIOS Y ENSAYOS}

de conocimiento nomotético, la lógica causal y metodologías experimentales y de corte cuantitativo. De forma complementaria, el paradigma hermenéutico concibe a la realidad como una construcción subjetiva a través de la interacción social, es decir, intersubjetiva. Su objetivo es comprender e interpretar los significados de los hechos sociales mediante metodologías cualitativas. Por último, el paradigma sociocrítico enfatiza la relación dialéctica entre las estructuras sociales y los individuos, y añade una dimensión ética, moral e ideológica. La meta del conocimiento es el de criticar, transformar, tomar conciencia de los procesos de formación del discurso y desvelar la función que ejerce el poder. No se identifica con ninguna metodología particular, pero dirige sus procedimientos a la acción y la práctica.

Tabla 1. Paradigmas de las Ciencias Sociales

\begin{tabular}{|c|c|c|c|}
\hline & POSITIVISTA & CONSTRUCTIVISTA & SOCIOCRÍTICO \\
\hline 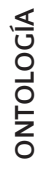 & La realidad es externa al sujeto & $\begin{array}{l}\text { La realidad es interpretativa: se } \\
\text { crea a través de interacciones } \\
\text { simbólicas entre los individuos, } \\
\text { que comunican significados }\end{array}$ & $\begin{array}{l}\text { La realidad es dialéctica: los individuos } \\
\text { están condicionados por las } \\
\text { estructuras sociales y a la vez pueden } \\
\text { transformarlas }\end{array}$ \\
\hline \multirow{4}{*}{ 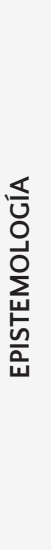 } & $\begin{array}{l}\text { La teoría es objetiva, } \\
\text { universal y neutra }\end{array}$ & La teoría es subjetiva & $\begin{array}{l}\text { La teoría es subjetiva y tiene una di- } \\
\text { mensión ética, moral e ideológica }\end{array}$ \\
\hline & Produce conocimiento nomotético & Produce conocimient & idiográfıco \\
\hline & $\begin{array}{c}\text { Busca explicar, controlar y predecir } \\
\text { analizando regularidades } \\
\text { y variables }\end{array}$ & $\begin{array}{c}\text { Busca comprender e } \\
\text { interpretar a partir de las } \\
\text { normas subyacentes a los } \\
\text { hechos sociales, así como las } \\
\text { interacciones y negociaciones } \\
\text { en las que se producen los } \\
\text { significados }\end{array}$ & $\begin{array}{c}\text { Busca criticar y transformar, tomando } \\
\text { autoconciencia del proceso de } \\
\text { formación social que establece las } \\
\text { condiciones en las que se desarrolla el } \\
\text { discurso práctico }\end{array}$ \\
\hline & Objetividad y causalidad & Intersubjetividad y motivación & Ideología, poder, identidad cultural \\
\hline \multirow{2}{*}{ 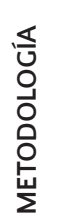 } & Preferencia cuantitativa & Preferencia cualitativa & $\begin{array}{c}\text { Combina metodologías cuantitativas y } \\
\text { cualitativas }\end{array}$ \\
\hline & $\begin{array}{c}\text { Experimental/manipulativa } \\
\text { y orientada a la verificación } \\
\text { de hipótesis }\end{array}$ & $\begin{array}{l}\text { Hermenéutica, fenomenológica, } \\
\text { etnográfica }\end{array}$ & Orientada a la acción \\
\hline
\end{tabular}

En su aplicación al terreno de la música, las características del paradigma sociocrítico implican el cuestionamiento de la propia naturaleza de la música y la revisión, desde un prisma ideológico y ético, de los procesos históricos en los que se han construido y normalizado las conceptualizaciones actualmente aceptadas y utilizadas. En este sentido, una educación musical crítica participaría en el debate entre las perspectivas formalistas y culturalistas del fenómeno musical (C. Rodríguez, 2002), descartando la objetividad y autonomía estéticas, y asumiendo un com- 
ponente intersubjetivo, contextual y funcional en los procesos de producción y recepción. Así, no situaría la belleza como rasgo intrínseco, en la línea del paradigma de la música absoluta (Dahlhaus, 2006), sino que entendería que esta se encuentra mediada por las características psíquicas del sujeto cognoscente y los sistemas culturales a los que este pertenece (Blacking, 2006).

Otras líneas de pensamiento musical que encajarían con los postulados críticos son las desarrolladas por la nueva musicología, que ponen en crisis conceptos establecidos y ampliamente extendidos como el de la obra de arte como objeto acabado (Goehr, 1994; Talbot, 2002) y la figura del compositor como genio trascendental que se constituye como modelo a imitar (Kant, 2007; Samson, 2001b; Wolff, 1996), así como el consecuente repertorio de obras canonizadas, que pretende mostrar su perfección atemporal frente a las contingencias del mundo contemporáneo (Gloag, 2015; Samson, 2001a). Además, este canon, propio de la estética musical occidental decimonónica, constituye una invención de raíces culturales y tradiciones por parte de la clase burguesa para afirmar su nuevo estatus, lo que le otorga una dimensión de ideología moral de los grupos culturalmente dominantes (Goehr, 2002; Samson, 2001a; Weber, 1992). En este sentido, algunos autores consideran el canon occidental como una construcción sobre la singularidad y unidad de la identidad cultural propia, y un desprecio sobre lo ajeno y lo diverso, constituyendo una forma encubierta de colonialismo, imperialismo, sexismo, racismo y elitismo (Bohlman, 1992; Citron, 2000; Helm, 1994). Desde esta perspectiva crítica, el canon ha sido visto como "un instrumento de exclusión, uno que legitima y refuerza las identidades y los valores de aquellos que ejercen el poder cultural” (Samson, 2001a, p. 2).

Una tercera perspectiva crítica es la constituida por el tratamiento culturalista que se realiza de las manifestaciones musicales, que se suele abordar desde tres tradiciones diferentes: el folklorismo, la musicología comparada y la etnomusicología (Pettan, 2015). En este sentido, una educación musical crítica sería consciente y señalaría la concepción esencialista de la música folklórica y tradicional que con frecuencia utilizan las políticas educativas para transmitir una ideología nacionalista y legitimadora del orden establecido (Dobrocká y Szórádová, 2018; Duraković, 2016; Ho, 2006, 2009, 2015; Ishii, 2018; Kennedy, 2016; Lee, 2006). Igualmente, sería sensible al tratamiento comparado que, bajo fórmulas del tipo otras músicas, se realiza de las manifestaciones musicales no occidentales, reduciéndolas a una alteridad homogeneizada o situándolas en estadios iniciales de un proceso teleológico que culmina en la música académica europea (Cámara, 2004; Hess, 2015; Nettl, 2015; Pettan, 2015). Finalmente, tendría una mayor afinidad con los presupuestos etnomusicológicos, los cuales tienen como objetivo el estudio de cualquier tipo de música siempre que este se realice en relación con su contexto cultural (Rice, 2013).

\subsection{Teorías educativas}

Una definición ya tradicional y ampliamente aceptada de teoría es la que proponen Lorenzo y Pla (2001, p. 64) cuando sostienen que "las teorías son explicaciones ideales y abstractas de los fenómenos, conocimientos desligados de una aplicación práctica, que regulan mediante reglas y leyes el comportamiento de los fenómenos y tienen un valor predictivo o explicativo”. Sin embargo, como apuntan otros autores, esta visión no agota el propio concepto de teoría. Existe 
un grupo de teorías orientadas hacia la práctica que "son preceptivas por naturaleza, ya que ofrecen orientaciones acerca del/os método/s a utilizar a la hora de conseguir de la mejor manera posible un objetivo dado" (Reigeluth, 2000, p. 17). Es decir, son teorías de naturaleza normativa o prescriptiva cuya voluntad es regular las acciones orientadas a unos fines determinados. Por otra parte, el postestructuralismo supera la asunción de una correlación entre teoría y práctica en la que la primera accede y desvela a la segunda, y defiende la inseparable unión entre la descripción simbólico-lingüística de la realidad y la realidad misma, transitando así de un concepto de teoría a otro de discurso o texto (Tadeu, 2001). Esto es, la función tradicional de descubrimiento de la realidad queda sustituida por la de construcción de esta.

Además, dentro del ámbito educativo, el grado de complejidad sociocultural que presentan sus procesos da lugar a una intersección de diferentes grupos de teorías que ven reflejada la dualidad descriptiva-explicativa y prescriptiva-normativa mencionada. Atendiendo a la clásica división del fenómeno educativo entre discente, docente y currículum, Reigeluth (2000) distingue entre las teorías del aprendizaje, las del diseño educativo y las curriculares, respectivamente. Así, mientras que las primeras son descriptivas y tienen un carácter psicologicista y epistemológico al tratar de estudiar la forma en la que se produce el conocimiento en los estudiantes, las otras dos son prescriptivas y centran su atención en el proceso de enseñanza. Sin embargo, estas últimas se distinguen en que las teorías del diseño educativo prescriben cómo debería ser la enseñanza desde una perspectiva metodológica mientras que las curriculares lo hacen desde el punto de vista de los contenidos, aunque ambas aparecen con frecuencia interrelacionadas. En consonancia con la estructura y los fines de esta investigación, aquí se presentan las teorías curriculares desde una perspectiva normativa.

Dado que las teorías son concreciones intelectuales construidas a través de los filtros paradigmáticos, estas encuentran una correspondencia con los paradigmas científicos. Así, bajo una similar nomenclatura, numerosos autores clasifican las teorías curriculares en tres grupos análogos a los tres paradigmas principales comentados anteriormente (Carr y Kemmis, 1988; De la Torre, 1993; Delgado, 1994; Escudero y González, 1984; R. García y Parra, 2010; Popkewitz, 1980; M. Rodríguez, 2002a; Sáez, 1989). De esta manera, el paradigma positivista produce teorías empírico-analíticas, tecnológicas, hipotético-deductivas, técnicas, racional-tecnológicas o técnico-burocráticas. Por su parte, el constructivista se concreta en teorías interpretativas, interpretativo-simbólicas, hermenéutico-deliberativas o prácticas. Finalmente, el paradigma sociocrítico se relaciona con teorías sociopolíticas, críticas o sociocríticas. La tabla 2 muestra de forma sintética las principales características de cada una de ellas a partir de lo expuesto por los autores mencionados. Como se puede observar, se ha optado por las categorías tecnológica, interpretativa y sociocrítica, por ser las más comunes. 


\section{ESTUDIOS Y ENSAYOS}

Tabla 2. Teorías curriculares

TECNOLÓGICA

Actividad técnica y controlable

que consiste en programar, realizar y evaluar

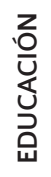

El docente es un técnico que aplica programas curriculares diseñados por expertos

El estudiante es un sujeto pasivo y moldeable
INTERPRETATIVA

SOCIOCRÍTICA
Actividad compleja sometida a los "juicios prácticos" de los docentes que consiste en reelaborar la cultura para compartirla con los estudiantes

El docente es un investigador sobre la acción que reflexiona y reelabora su práctica

El estudiante es un sujeto activo que construye el conocimiento a partir de sus ideas previas
Actividad crítica, moral y política que consiste en la transformación social y la emancipación individual y colectiva

El docente es un intelectual transformativo

El estudiante es un sujeto activo que construye su identidad a partir de la interacción social

\begin{tabular}{|c|c|c|c|}
\hline 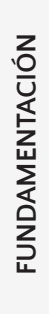 & $\begin{array}{c}\text { Aprendizaje teórico, lineal y par- } \\
\text { celado }\end{array}$ & $\begin{array}{l}\text { Cognitivo-constructivismo } \\
\text { (desarrollo endógeno) } \\
\text { Aprendizaje práctico enfocado } \\
\text { hacia el proceso }\end{array}$ & $\begin{array}{c}\text { Socioconstructivismo } \\
\text { Aprendizaje participativo a } \\
\text { través la interacción social, } \\
\text { la negociación curricular y la } \\
\text { crítica ideológica }\end{array}$ \\
\hline \multirow{3}{*}{ 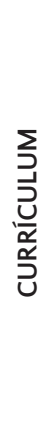 } & Cerrado & \multicolumn{2}{|l|}{ Flexible y abierto } \\
\hline & $\begin{array}{l}\text { Enfocado a la consecución eficaz } \\
\text { de los resultados }\end{array}$ & Enfatiza los procesos de aprendizaje & $\begin{array}{l}\text { Es una construcción histórica } \\
\text { que reproduce las relaciones } \\
\text { de poder }\end{array}$ \\
\hline & $\begin{array}{l}\text { Articulado en torno a unos objeti- } \\
\text { vos prefijados, a los que se subor- } \\
\text { dinan los medios, los contenidos y } \\
\text { la evaluación }\end{array}$ & $\begin{array}{l}\text { Las actividades están contextualizadas, los } \\
\text { contenidos se presentan problematizados y } \\
\text { la evaluación es continua }\end{array}$ & $\begin{array}{l}\text { Los elementos curriculares } \\
\text { deben consensuarse a través } \\
\text { de la participación social }\end{array}$ \\
\hline \multirow{2}{*}{ 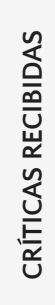 } & $\begin{array}{l}\text { Fragmentación y descontextuali- } \\
\text { zación del conocimiento } \\
\text { Papel pasivo del docente }\end{array}$ & \multirow[t]{2}{*}{$\begin{array}{l}\text { Olvida la influencia de las estructuras } \\
\text { sociales en los procesos educativos }\end{array}$} & $\begin{array}{c}\text { Teorías formales con poco } \\
\text { contenido y escasa } \\
\text { aplicación }\end{array}$ \\
\hline & $\begin{array}{l}\text { Excesivo protagonismo } \\
\text { de los resultados }\end{array}$ & & Propuestas mesiánicas \\
\hline
\end{tabular}

A pesar del amplio consenso en esta división ternaria, algunos autores solo reconocen los dos primeros grupos de teorías (Angulo y Blanco, 1994; Area, 1991; Sanjosé, 1994). Por otro lado, Tadeu (2001) diferencia entre teorías tradicionales, críticas y postcríticas. No obstante, aquí se considera a las dos últimas dentro del grupo de las teorías sociocríticas, ya que ambas apelan a las relaciones dialécticas entre individuo y sociedad, y a la educación como herramienta de transformación. 
En el campo de la educación musical, tres tradiciones actualmente activas encajan con las teorías curriculares sociocríticas: Critical Pedagogy for Music Education (Abrahams, 2005; Gowan, 2016), Music Education for Social Justice (Benedict et al., 2015; Gould et al., 2009) y Culturally Responsive Teaching in Music Education (Lind y McKoy, 2016). Si bien cada una de ellas presenta su propia idiosincrasia, fruto de una génesis y evolución diferenciadas, todas ellas convergen en los planteamientos críticos que aquí se han señalado. Así, sostienen que la educación musical es una práctica política que tiene que favorecer la reflexión sobre los sistemas opresivos y las injusticias sociales (Shaw, 2012), y la adquisición de una conciencia crítica y problematizadora del conocimiento, cuestionando los repertorios canónicos, los que reproducen estereotipos racistas o sexistas, y los que representan algún tipo de exclusión, así como los sistemas de aprendizaje tradicionales basados en la notación escrita que pueden suponer una barrera estructural de acceso para estudiantes sin formación musical específica (Vaugeois, 2009).

Además, una educación musical crítica debe ser consciente de la distribución vertical del poder en espacios como el aula o el centro educativo, lo que requiere una reflexión sobre la toma de decisión y una apertura hacia los intereses y experiencias de los estudiantes (Abrahams, 2007), de forma que estos puedan participar en la selección de contenidos como el repertorio (Younker y Hickey, 2007) y se genere un diálogo entre estudiantes y docentes en el que compartan sus músicas y se reconozcan mutuamente (Abrahams, 2005; Gowan, 2016). Es decir, se trata de un tipo de educación centrada en el estudiante y no en un currículum apriorístico (Shaw, 2012), haciéndoles conscientes de sus propias vidas musicales (O’Neill, 2015). Esto implicará el establecimiento de puentes entre la música que viven los estudiantes en su día a día y la que se enseña en la escuela, reconociendo e incorporando sus preferencias e identidades musicales (Hebert, 2009). Asimismo, al estar estas conformadas por la música popular urbana de su tiempo presente, esto permitirá una reflexión crítica sobre su propia contemporaneidad (Johnson, 2009).

Por otra parte, el docente se deberá plantear su cultura musical y reflexionará sobre la manera en la que puede influir en los procesos de enseñanza y aprendizaje en los que participa (Lind y McKoy, 2016; Thompson, 2015; Wiens, 2015). Del mismo modo, deberá ser capaz de identificar las prácticas etnocéntricas y diseñar estrategias de enseñanza que no sean discriminatorias con respecto a categorías culturales como la raza, el género o la orientación sexual (Koza, 2009), además de trascender los postulados de la musicología tradicional y el modelo educativo de los conservatorios, y trabajar en diálogo constante con otras disciplinas que también abordan el fenómeno musical.

\subsection{Modelos didácticos}

Los modelos didácticos son "representaciones valiosas y clarificadoras de los procesos de enseñanza-aprendizaje, que facilitan su conocimiento y propician la mejora de la práctica, al seleccionar los elementos más pertinentes y descubrir la relación de interdependencia que se da entre ellos” (Medina, 2002, p. 61). Al fin y al cabo, un modelo es una representación, abstracción o idealización de una determinada realidad que contribuye a su comprensión teórica (Escudero, 1981; Portides, 2008), por lo que aplicado al campo de la educación puede ser útil para organizar tanto la investigación como la intervención en el aula (J. Gimeno, 1981; Jorquera, 2010). Dicho 
en otras palabras, es "un esquema mediador entre la realidad y el pensamiento, entre el mundo y la ciencia” (J. Gimeno, 1981, p. 96), construido a partir de enunciados teóricos y observaciones empíricas (Calvo, 2006). En la misma línea, Heinich (1975) plantea que un modelo se relaciona con la teoría en tanto que representación de su estructura y con el objeto de estudio en tanto que réplica isomorfa de su estado original. Sin embargo, este isomorfismo nunca es completo, por lo que requiere una visión multimodélica que desvele las diferentes caras de una misma realidad (Bunge, 1985; Cartwright, 1999; Frigg y Nguyen, 2017; J. Gimeno, 1981; Knuuttila, 2005).

Por lo que respecta específicamente a los modelos didácticos, es decir, aquellos que recrean los procesos de enseñanza-aprendizaje desde la perspectiva del docente, estos pueden dividirse en dos grandes grupos. De una parte, aquellos que representan dimensionalmente el fenómeno educativo definiendo sus componentes principales (e. g., Escudero, 1981; Escudero y González, 1984; J. Gimeno, 1981; M. Lorenzo, 1986; M. Rodríguez, 1997). De la otra, aquellos en los que dichas dimensiones adoptan valores concretos que representan una práctica específica, por lo que son utilizados como estilos de enseñanza (e. g., Aróstegui, 2014; F. F. García, 2000; F. J. García, 2014; Hernández y Guárate, 2017; Jorquera, 2010; M. Rodríguez, 2002b). En adelante, los primeros serán llamados modelos dimensionales y los segundos modelos aplicados. Dentro del primer grupo, Gimeno (1981) define los modelos mediante tres dimensiones: aspectos psicológicos relacionados con el concepto de sujeto, aspectos didácticos relacionados con el aprendizaje y los medios de comunicación pedagógica, y aspectos relacionados con la identidad y valor del conocimiento. De igual manera, frente a la imposibilidad isomórfica, propone cuatro tipos complementarios de modelo: formales, psicológicos, estructurales y procesuales.

Otras clasificaciones de los modelos son las propuestas por Escudero (1981), quien establece una distinción entre modelos de aprendizaje para el dominio y modelos sistemáticos; Escudero y González (1984), que distinguen entre sistémico-ambientalistas, organizativos, centrados en estilos de decisión, centrados en los individuos, y de investigación-decisión y difusión; o Lorenzo (1986), quien diferencia entre clásico-tradicionales y sistémico-tecnológicos (M. Lorenzo, 1986). También se encuentran las de M. Rodríguez (1997), que presenta el tecnológico, el humanista y el ecológico-comunicativo; Pont (2002) que agrupa modelos en tecnológicos, flexibles y contextuales; o Medina (2002) que propone el modelo de aprendizaje para el dominio, el comunicativo-interactivo, el contextual y el colaborativo.

La distinción de M. Rodríguez (1997) encuentra en este trabajo especial interés por presentar tres modelos de un gran nivel de abstracción que se encuentran relacionados con los paradigmas científicos y las teorías curriculares presentados anteriormente. En el modelo tecnológico, el elemento central son los objetivos, que son evaluados y condicionan los contenidos y los métodos (ilustración 1). En el modelo humanista el centro se sitúa en la figura del docente, que interpreta las interacciones que tienen lugar en el aula, y por el que pasan todos los elementos del sistema de enseñanza-aprendizaje (ilustración 2). Por último, el modelo ecológico-comunicativo plantea un gran número de relaciones a través de las cuales conecta el mundo fuera del centro con la vida dentro del aula, la vez que complejiza los elementos dentro de ella (ilustración 3).

Dentro del grupo de modelos aplicados, aquellos con un menor nivel de abstracción y una mayor definición de la práctica educativa concreta, existen también diversas clasificaciones. Por ejemplo, F. F. García (2000) y F. J. García (2014) diferencian entre tradicional, tecnológico, espontaneís- 


\section{ESTUDIOS Y E N SAYOS}

ta y alternativo; Pont (2002) entre el socrático, el tradicional y el activo; y Rodríguez (2002b) entre orientado por la filosofía del liberalismo o por la teoría crítico-comunicativa. Por su parte, Hernández y Guárate (2017) utilizan el concepto de modelo didáctico de un modo todavía más concreto y lo equiparan a técnicas o estrategias docentes, como la clase expositiva, magistral o teórica, la lectura, la interrogación didáctica, organizadores de la información, la observación, la demostración, el debate o la dramatización, entre otras. Todos los modelos nombrados se pueden sintetizar en cuatro: el tradicional, el tecnológico, el activo-espontaneísta y el crítico-alternativo (tabla 3), tomando el socrático como una técnica de enseñanza en lugar de como un modelo.

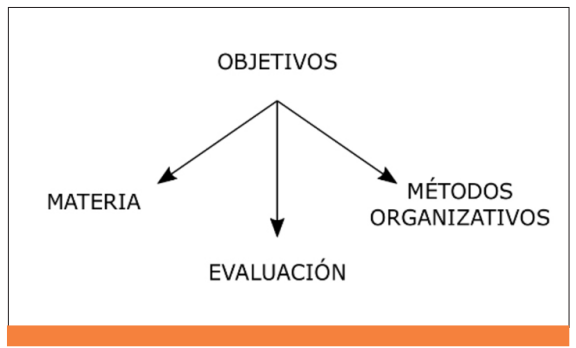

Ilustración 1. Modelo tecnológico (Rodríguez, 1997)

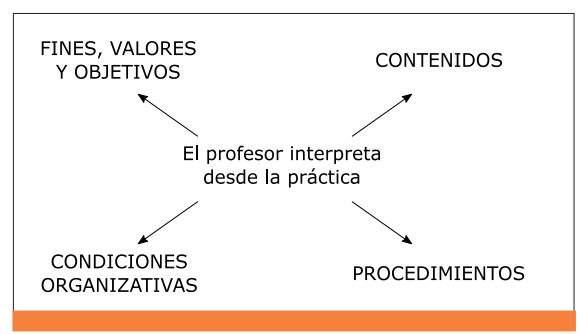

Ilustración 2. Modelo humanista (Rodríguez, 1997)

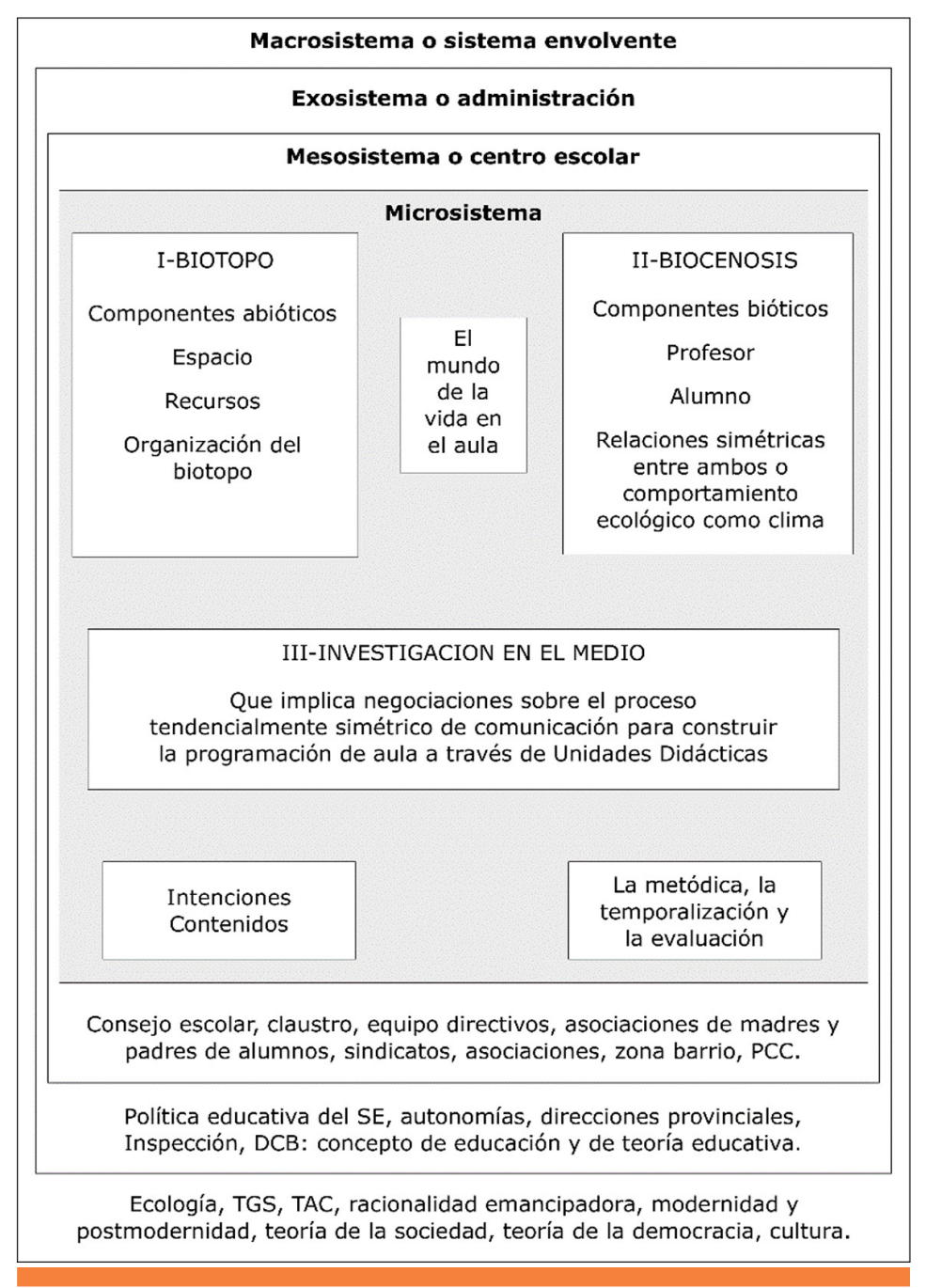

Ilustración 3. Modelo ecológico-comunicativo (Rodríguez, 1997)

El primero se centra en contenidos disciplinares transmitidos magistralmente por un docente y memorizados pasivamente por un alumno sometido a una disciplina represiva (F. F. García, 2000; F. J. García, 2014; Pont, 2002). El segundo está basado principalmente en objetivos que son operativizados mediante contenidos seleccionados por expertos y alcanzados a través de secuencias sistemáticas de actividades (F. F. García, 2000; F. J. García, 2014). Por su parte, el modelo orientado por la filosofía del liberalismo es una mezcla de los dos primeros, especialmente del tecnológico, que pone el énfasis en principios como el relativismo moral, la competitividad como instrumento de promoción, la libertad por encima de la igualdad, el individualismo, la ra- 


\section{ESTUDIOS Y ENSAYOS}

cionalidad instrumental y, la subordinación de la escuela a las leyes de mercado (M. Rodríguez, 2002b). Por esto, aquí no se trata como modelo independiente.

El tercer modelo, el activo-espontaneísta, sitúa al estudiante en el centro y se enseña mediante actividades prácticas, abiertas y flexibles, evaluando no solo conceptos, sino también destrezas y actitudes (F. F. García, 2000; F. J. García, 2014; Pont, 2002). Finalmente, el modelo críticoalternativo utiliza la investigación para enriquecer las experiencias de los estudiantes, analizar críticamente la sociedad y producir cambios. Además, tiene una base ética y los contenidos son interdisciplinares (F. F. García, 2000; F. J. García, 2014; M. Rodríguez, 2002b).

Tabla 3. Modelos didácticos

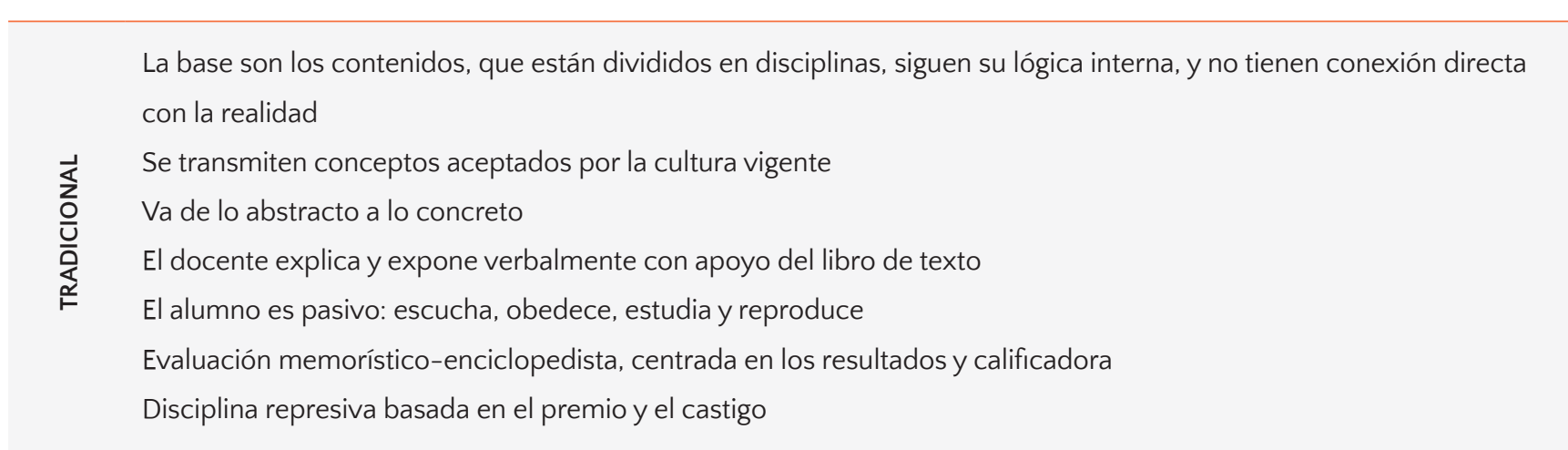

La base son los objetivos, hacia cuya consecución se dirigen el resto de elementos didácticos

U Utiliza programaciones didácticas muy detalladas

Se transmiten contenidos actualizados y preparados por expertos

No se tienen en cuenta los intereses de los estudiantes, quienes realizan sistemáticamente actividades programadas

La evaluación mide detalladamente los aprendizajes mediante test y ejercicios específicos, atendiendo principalmente a los resultados

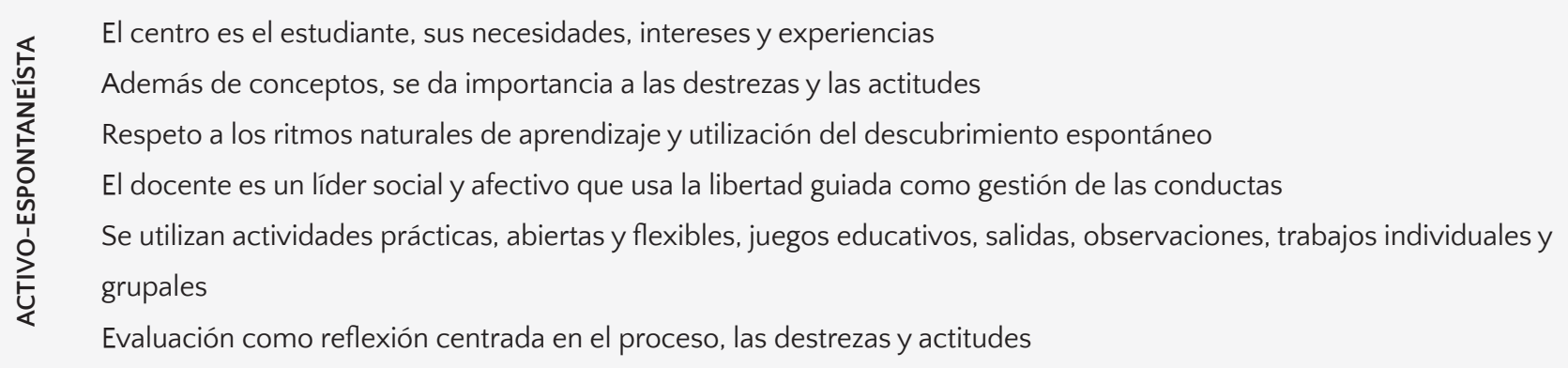

Basado en la investigación como proceso de búsqueda y acción por parte del docente y los estudiantes para comprender críticamente la realidad social y producir cambios

Problematización de las experiencias vitales desde una perspectiva ética

Parte de los intereses e ideas de los estudiantes para enriquecerlos progresivamente

Carácter sistémico de los diferentes elementos curriculares e interdisciplinar

Persigue valores educativos como la autonomía, la igualdad, el respeto a la diversidad, la cooperación o la solidaridad El docente es un coordinador e investigador 


\section{EST U D O S Y E N SAYOS}

En el campo concreto de la educación musical, Jorquera (2010) ha realizado una propuesta de cuatro modelos que guardan relación con los anteriores. Se trata del modelo académico, el práctico, el comunicativo lúdico y el complejo (tabla 4). De forma sintética, en los dos primeros el alumno tiene un papel pasivo de recepción cultural de las grandes obras canonizadas, bien a través de la teoría y la lectoescritura en el académico, bien a través de la práctica irreflexiva en el práctico. En el modelo comunicativo lúdico se tienen en cuenta los intereses del alumnado cuyo disfrute, motivación y entretenimiento, son el objetivo principal. Finalmente, el modelo complejo concibe la educación musical como un proceso de investigación que parte de las ideas e intereses de los estudiantes y aborda la música desde una perspectiva culturalista, poniendo énfasis en sus significados y funciones contextuales. Además, pretende capacitar a los alumnos para comprender críticamente su realidad y participar en ella para poder transformarla.

Tabla 4. Modelos didácticos aplicados a la educación musical (Jorquera, 2010)

\begin{tabular}{|c|c|}
\hline \multirow{5}{*}{ 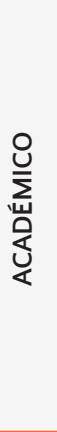 } & $\begin{array}{l}\text { Papel central de la lectoescritura tradicional, la asimilación de conceptos teóricos, el análisis de las formas y es- } \\
\text { tructuras musicales, la audición de obras con explicación previa y la memorización enciclopédica, anecdótica o } \\
\text { episódica de compositores y períodos históricos }\end{array}$ \\
\hline & $\begin{array}{l}\text { El conocimiento está establecido por expertos, formado por repertorios canonizados por la tradición (grandes } \\
\text { obras) y desligado de la vida de los estudiantes }\end{array}$ \\
\hline & Separación entre teoría y práctica, y gran importancia de los libros de texto \\
\hline & La práctica musical se trabaja a través de la imitación y la repetición \\
\hline & El objetivo es aumentar la cultura que los estudiantes deben adquirir de forma acrítica \\
\hline \multirow{6}{*}{ 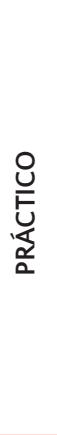 } & $\begin{array}{l}\text { Papel central de la práctica irreflexiva de actividades, como tocar instrumentos, cantar, improvisar o componer, sin } \\
\text { referencias al significado comunicativo, social ni cultural }\end{array}$ \\
\hline & La práctica musical se trabaja a través de la imitación y la repetición \\
\hline & Espera que el alumnado disfrute y experimente vivencias afectivas \\
\hline & $\begin{array}{l}\text { El repertorio es similar al académico, aunque con la posibilidad de introducir materiales más atractivos, adaptados, } \\
\text { con una presentación más agradable y motivadores }\end{array}$ \\
\hline & No se tienen en cuenta las ideas e intereses de los estudiantes y no se fomenta su autonomía \\
\hline & La música pretende neutralidad y tiene un uso ornamental \\
\hline \multirow{6}{*}{ 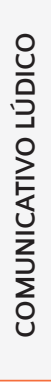 } & $\begin{array}{l}\text { Papel central de la motivación del alumnado, quien participa y es entretenido mediante actividades lúdicas próxi- } \\
\text { mas a la cultura del espectáculo }\end{array}$ \\
\hline & En las actividades musicales se introducen significados comunicativos y expresivos, aunque descontextualizados \\
\hline & El repertorio puede ser parcialmente consensuado entre docente y estudiantes, teniendo en cuenta los intereses \\
\hline & de estos últimos, aunque no sus ideas \\
\hline & La evaluación puede ser parcialmente participativa y mide resultados y algunos procesos \\
\hline & Se implementan las metodologías activas: Orff, Kodaly, Willems, Dalcroze, etc. \\
\hline \multirow{5}{*}{ 을 } & $\begin{array}{l}\text { Papel central de la investigación sobre significados, contextos, funciones y estructuras de la música, que se conci- } \\
\text { be como un elemento cultural }\end{array}$ \\
\hline & $\begin{array}{l}\text { Se establecen conexiones entre la música y la cultura propia para comprenderla, participar críticamente en ella y } \\
\text { transformarla, así como con otras culturas }\end{array}$ \\
\hline & Se busca el disfrute y la comunicatividad musical \\
\hline & $\begin{array}{l}\text { El repertorio está consensuado ente profesores y estudiantes, siendo las ideas e intereses de estos últimos el punto } \\
\text { de partida para los aprendizajes }\end{array}$ \\
\hline & La evaluación utiliza diversas herramientas, es consensuada y mide procesos y resultados \\
\hline
\end{tabular}




\section{ESTUDIOS Y E N A YOS}

Por su parte, Aróstegui (2014) también establece una distinción de tres modelos didácticos que, aunque con algunas diferencias, responden a la lógica ternaria que se ha presentado anteriormente. Utilizando el concepto de enfoque como equivalente a modelo, el autor diferencia entre técnico, práctico y crítico. El primero prioriza la teoría y la técnica frente a la práctica y la interpretación, y exige un gran esfuerzo para conseguir los resultados deseados. El segundo, de forma contraria, prefiere comenzar vivenciando la música mediante actividades de movimiento y audición, para después racionalizarla. En cuanto al tercero, este es crítico con el repertorio canónico de la música académica occidental de tradición europea y propone una música intercultural que incorpore repertorios propios de diferentes grupos sociales. Además, pretende contribuir a la conformación del gusto musical de los estudiantes.

Como se puede observar, Jorquera (2010) y Aróstegui (2014) utilizan el concepto de modelo práctico de forma diferente. Así, para la primera no es más que el modelo académico que modifica su metodología mediante la descentralización de la teoría y un mayor protagonismo de actividades prácticas, manteniendo el resto de características casi invariables. Sin embargo, el segundo autor lo relaciona con el movimiento de Escuela Nueva y las metodologías activas. Es decir, lo que para Aróstegui (2014) es el modelo práctico, para Jorquera (2010) es el comunicativo lúdico. Aquí se mantendrán las dos acepciones del concepto de modelo práctico.

Tabla 5. Modelos didácticos aplicados a la educación musical (Aróstegui, 2014)

\section{을}

Primero se aprende la teoría musical y la lectoescritura, y luego la práctica

Primero se aprende la técnica y luego la interpretación

El aprendizaje consiste en conseguir resultados que requieren un esfuerzo

Primero se siente y vivencia la música, y luego se piensa y teoriza

A través de ejercicios de movimiento y audición se interiorizan los parámetros musicales

Se implementan las metodologías activas: Orff, Kodaly, Willems, Dalcroze, etc.

Crítica a la hegemonía de la música clásica, culta o de varones blancos muertos, ejercida por su relación con las clases dominantes

Educación musical intercultural en la que se incluyen géneros y estilos propios de diferentes grupos sociales

Utilización de grafías no convencionales como primer paso hacia la notación

Contribuir a la construcción del gusto musical de los estudiantes desarrollando la capacidad de juicio autónomo y crítico

\section{CONCLUSIONES: HACIA UNA EDUCACIÓN MUSICAL CRÍTICA}

En este trabajo se ha realizado una revisión bibliográfica de tipo narrativo con el objetivo de aproximarse a una caracterización de la educación musical crítica. Para ello, se ha partido de los conceptos de paradigma cientifico, teoría curricular y modelo didáctico, desarrollados por la didáctica general, se han identificado sus formulaciones críticas y se han proyectado los postulados de estas últimas sobre las disciplinas de la musicología y la educación musical. De esta forma, se ha observado que estos tres conceptos, en tanto que diferentes niveles del proceso que relaciona la construcción del conocimiento con su aplicación práctica, guardan una inevitable relación, tal y 


\section{ESTUDIOS Y ENSAYOS}

como muestra la tabla 6. Es lógico, puesto que cada marco formal de coordenadas ontológicas, epistemológicas y metodológicas determinadas, dará lugar a un tipo de teoría o grupo de teorías particulares y, a su vez, estos se concretarán de forma coherente en modelos dimensionales y aplicados a la realidad. Además, los tres niveles pueden servir como parámetros constitutivos de un determinado tipo de enfoque educativo. Siguiendo con la línea argumental de este trabajo, se han identificado tres tipos: el tradicional, el constructivista y el crítico (tabla 6). A partir de dicha diferenciación es posible conceptualizar una educación musical crítica, que se sintetiza a continuación.

Tabla 6. Tipos de enfoque educativo. Fuente. Tabla de elaboración propia

\begin{tabular}{|c|c|c|c|c|}
\hline & PARADICMAS & TEORÍAS & MODELOS (GENERAL) & MODELOS (MÚSICA) \\
\hline 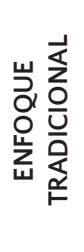 & $\begin{array}{c}\text { Positivista, } \\
\text { empírico- } \\
\text { analítico, racional- } \\
\text { tecnológico }\end{array}$ & $\begin{array}{l}\text { Tecnológica, técnica, } \\
\text { empírico-analítica, } \\
\text { hipotético-deductiva, } \\
\text { racional-tecnológica, } \\
\text { técnico-burocrática }\end{array}$ & $\begin{array}{c}\text { Tecnológico, aprendizaje } \\
\text { para el dominio, tradicional, } \\
\text { clásico }\end{array}$ & $\begin{array}{l}\text { Académico, } \\
\text { práctico, técnico }\end{array}$ \\
\hline 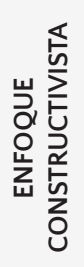 & $\begin{array}{l}\text { Hermenéutico, } \\
\text { constructivista, } \\
\text { simbólico, } \\
\text { interpretativo }\end{array}$ & $\begin{array}{c}\text { Interpretativa, } \\
\text { simbólica, } \\
\text { hermenéutico- } \\
\text { deliberativa, práctica }\end{array}$ & $\begin{array}{l}\text { Humanista, flexible, } \\
\text { comunicativo, interactivo, } \\
\text { activo, espontaneísta }\end{array}$ & $\begin{array}{l}\text { Comunicativo } \\
\text { lúdico, práctico }\end{array}$ \\
\hline 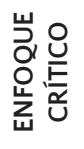 & $\begin{array}{l}\text { Sociocrítico, } \\
\text { crítico, teoría } \\
\text { crítica }\end{array}$ & $\begin{array}{l}\text { Sociocrítica, crítica, } \\
\text { sociopolítica }\end{array}$ & $\begin{array}{l}\text { Ecológico-comunicativo, } \\
\text { colaborativo, contextual }\end{array}$ & Complejo, crítico \\
\hline
\end{tabular}

En primer lugar, dicha educación concibe la construcción del conocimiento desde un paradigma sociocrítico. Esto es, entiende que la realidad es construida de forma dialéctica por sujetos que se encuentran condicionados por estructuras sociales y a la vez están dotados de agencia para transformarlas. Desde el punto de vista de la epistemología, la teoría es ética, moral, ideológica, generadora de identidades culturales y está atravesada por el poder. Por eso, produce un tipo de conocimiento idiográfico y busca tomar conciencia crítica de las condiciones sociohistóricas en las que se desarrollan los discursos. A nivel metodológico, puede utilizar metodologías tanto cuantitativas como cualitativas, pero las orienta a la acción, la concienciación y la transformación.

Es decir, la educación musical crítica aborda la forma en que se concibe la propia música como objeto social y su dimensión estética, y plantea una revisión de las conceptualizaciones aprendidas y reproducidas mediante la práctica, como la música autónoma, la obra de arte, el genio compositor o el repertorio canónico. Así, por ejemplo, no sitúa la belleza sobre el objeto musical en sí mismo, sino sobre un sujeto cognoscente cuya percepción viene determinada por 
sus propias experiencias vitales. De esta forma, el papel hegemónico que ejerce la música académica occidental en base a una supuesta superioridad inherente y objetiva se sustituye por una dialéctica según la cual el individuo emite una serie de juicios estéticos que a su vez están condicionados por procesos de enculturación ejercidos por los sistemas educativos, los medios de comunicación o las redes sociales en las que participa. Además, la educación musical crítica desvela los mecanismos históricos que han otorgado a la música académica occidental un estatus de superioridad con respecto al resto de manifestaciones artísticas.

Igualmente, la educación musical crítica cuestiona la visión esencialista de la cultura que se construyó durante el siglo XIX como parte de la definición de los nacionalismos y que impone de forma apriorística un conjunto de repertorios folklorizados sobre un territorio concreto como parte de la concepción de un nosotros. De la misma forma, señala el tratamiento simplificador y subordinado con el que se concibe la música de diferentes partes del mundo al tratarla, por contraposición a aquella, como la otra música. En cuanto a la música popular urbana, la educación musical crítica reconoce que esta construye las identidades culturales de los estudiantes, y a la vez se plantea los mecanismos de homogeneización cultural que les afectan como resultado de los procesos de globalización económica.

En segundo lugar, la educación musical crítica se fundamenta en una teoría curricular sociocrítica. Es decir, concibe a la educación como una actividad política, crítica y moral que consiste en la transformación social y la emancipación individual y colectiva. El docente es un intelectual transformativo, mientras que el estudiante es un sujeto activo que construye su realidad de forma socioconstructivista a partir de la interacción social, la negociación curricular y la crítica ideológica. Por último, el currículum es una construcción histórica que reproduce las relaciones de poder, de forma que este debe consensuarse colectivamente y debe mantenerse flexible y abierto.

Esto es, la educación musical crítica se plantea las formas históricas que han condicionado la construcción del currículum en sus diferentes niveles, trata de desvelar los mecanismos de poder y los intereses ocultos que pudieran ejercer algún tipo de influencia en el mismo, y construye un currículum alternativo desde una ética concreta que comparte y negocia con otros miembros de la comunidad educativa, entre los que se encuentran los estudiantes. Por ejemplo, se cuestiona el tratamiento academicista y nacionalista que recibe la música en la educación formal, el cual se encuentra influido por la educación de conservatorio que han recibido sus diseñadores y los intereses de las estructuras políticas que promulgan los diferentes decretos de desarrollo curricular. Frente a eso, renegocia un repertorio y unas formas de aprendizaje que reconocen e incluyen a la diversidad de identidades musicales presentes en el aula y, a partir de estas, los amplían incorporando otras que existen en otros sistemas sociales. Además, ofrece herramientas a los estudiantes para comprender su entorno social a través de sus identidades musicales. Por ejemplo, facilita la comprensión del gusto musical propio y la capacidad de emitir juicios críticos sobre las narrativas de las músicas que consumen.

Por último, la educación musical crítica implementa modelos como el ecológico-comunicativo, el contextual, el colaborativo, el crítico y el complejo. En este sentido, conecta de forma sistémica la vida en el aula con otros niveles contextuales como el centro escolar, la comunidad educativa, la administración educativa o los movimientos sociales, pudiendo llegar a construir 
comunidades de aprendizaje. El docente coordina a los estudiantes y persigue valores como la autonomía, la igualdad, el respeto a la diversidad, la cooperación o la solidaridad. Utiliza la investigación como método para que los estos construyan el conocimiento, analicen críticamente la sociedad y produzcan cambios, y problematiza las experiencias, intereses e ideas de los estudiantes desde una lógica ética e interdisciplinar.

En este nivel, la educación musical crítica establece metodologías participativas y democráticas en las que se tienen en cuenta los deseos a intereses de los estudiantes. Así, la decisión sobre el repertorio y las formas de aprendizaje son elegidas mediante mecanismos como el voto individual, la búsqueda de consensos y la argumentación sobre la idoneidad de trabajar unas músicas u otras. Igualmente, se establecen sistemas de reflexión y debate en los que, a través del diálogo igualitario, se comparten diferentes puntos de vista sobre las implicaciones sociales y estéticas de unos u otros estilos musicales, artistas o piezas determinadas, así como del trabajo realizado en el aula. Igualmente, se fomenta el trabajo colaborativo mediante actividades de creación musical en pequeños equipos, y se implementan sistemas de evaluación formativa en los que los estudiantes auto-y co-evalúan sus propios aprendizajes.

En síntesis, una educación musical crítica podría definirse por (1) la resignificación de la propia idea de música mediante el juicio crítico de los conceptos que históricamente se han construido en torno a la misma y que han experimentado un proceso de normalización que llega hasta la actualidad, presentándolos como naturales y dados; (2) el desvelamiento y superación de las relaciones de poder que subyacen en las experiencias musicales, en especial las que generan algún tipo de exclusión en los contextos educativos, y (3) la utilización de prácticas democráticas que favorezcan el reconocimiento de la diversidad, la participación y el desarrollo de un pensamiento crítico sobre la dialéctica entre música y sociedad. Este tipo de educación musical contribuirá a la conformación de un de sujeto consciente de su biografía musical y de la relación de esta con las problemáticas sociales del entorno en el que habita, facilitando así su capacidad de generar e implementar procesos de emancipación personal y de transformación social.

\section{REFERENCIAS}

Abrahams, F. (2005). The Application of Critical Pedagogy to Music Teaching and Learning. Visions of Research in Music Education, 6, 1-16. https://doi.org/10.1177/87551233050230020103

Abrahams, F. (2007). Musicing Paulo Freire: a critical pedagogy for music education. En P. McLaren y J. L. Kincheloe (Eds.), Critical Pedagogy: Where Are We Now? (pp. 223-237). Nueva York: Peter Lang.

Allen, R., y Torres, C. A. (2003). Llegint Freire i Habermas. Pedagogía crítica y cambio social. Xàtiva: Edicions del Crec i Denes Editorial.

Angulo, J. F., y Blanco, N. (1994). Teoría y desarrollo del currículum. Archidona: Aljibe.

Area, M. (1991). Los medios, los profesores y el currículo. Barcelona: Sendai.

Aróstegui, J. L. (2014). Fundamentos del currículo para la educación musical. En J. L. Aróstegui (Ed.), La música en Educación Primaria. Manual de formación del profesorado (pp. 19-42). Madrid: Dairea.

Aubert, A., Duque, E., Fisas, M., y Valls, R. (2010). Dialogar y transformar. Pedagogía crítica del siglo XXI. Barcelona: Graó. 


\section{ESTUDIOS Y ENSAYOS}

Ayuste, A., Flecha, R., López, F., y Lleras, J. (2003). Planteamientos de la pedagogía crítica. Barcelona: Graó.

Benedict, C., Schmidt, P., Spruce, G., y Woodford, P. (Eds.). (2015). The Oxford Handbook os Social Justice in Music Education. New York: Oxford University Press.

Blacking, J. (2006). How musical is man? Seattle y London: University of Washington Press.

Bohlman, P. V. (1992). Epilogue: Musics and Canons. En K. Bergeron y P. V Bohlman (Eds.), Disciplining Music (p. 210). Chicago: The University of Chicago Press.

Bunge, M. (1985). Teoría y realidad. Barcelona: Ariel.

Calvo, D. (2006). Modelos teóricos y representación del conocimiento. Universidad Complutense de Madrid.

Cámara, E. (2004). Etnomusicología. Madrid: Ediciones del ICCMU.

Carbonell, J. (2015). Pedagogías del siglo XXI. Barcelona: Octaedro.

Carr, W., y Kemmis, S. (1988). Teoría crítica de la enseñanza: la investigación-acción en la formación del profesorado. Barcelona: Martínez Roca.

Cartwright, N. (1999). The dappled world: A study of the boundaries of science. Cambridge: Cambridge University Press.

Cascante, C., y Martínez, J. (2013). Pedagogía Crítica, treinta años después. Revista Interuniversitaria de Formación del Profesorado, 77, 15-21. https://dialnet.unirioja.es/ejemplar/377845

Citron, M. J. (2000). Gender and the Musical Canon. Urbana: University of Illinois Press.

Dahlhaus, C. (2006). La idea de la Música absoluta. Barcelona: Idea Música.

De la Torre, S. (1993). Didáctica y currícuo. Bases y componentes del proceso educativo. Madrid: Dykinson.

De Miguel, M. (1988). Paradigmas de la investigación educativa española. En I. Dendaluce (Ed.), Aspectos metodológicos de la investigación educativa (pp. 60-77). Madrid: Narcea.

Delgado, M. L. (1994). Teorías curriculares. En Didáctica general. Un enfoque curricular (pp. 89-111). Alcoy: Marfil.

Dobrocká, S., y Szórádová, E. (2018). School curriculum as a means of shaping national identity: music education in the Slovak region of Czechoslovakia in the interwar period (1918-1939). Pedagogy, Culture and Society, 26(2), 165-179. https://doi.org/10.1080/14681366.2017.1365751

Duraković, L. (2016). Music as the educational mean in the making of the «socialist man»: Music education in primary schools of Croatia (1945-1965). History of Education and Children's Literature, 11(2), 267-289. https://doi.org/10.1400/248466

Escudero, J. M. (1981). Modelos didácticos. Barcelona: Oikos-tau.

Escudero, J. M., y González, M. T. (1984). La renovación pedagógica: algunos modelos teóricos y el papel del profesor. Madrid: Escuela Española.

Freire, N. (2009). Contribuciones de Paulo Freire a la Pedagogía Crítica: «Educación emancipatoria: la influencia de Paulo Freire en la ciudadanía global» o «La influencia de Paulo Freire en una educación para la libertad y la autonomía». Revista Electrónica Teoría de la Educación. Educación y Cultura en la Sociedad de la Información, 10, 141-158. http://dx.doi.org/10.14201/eks.3967 


\section{EST U D O S Y E N SAYOS}

Frigg, R., y Nguyen, J. (2017). Scientific Representation is Representation-As. En H.-K. Chao y J. Reiss (Eds.), Philosophy of Science in Practice. Nancy Cartwright and the Nature of Scientific Reasoning (pp. 149-179). Durham: Springer.

García, F. F. (2000). Los modelos didácticos como instrumento de análisis y de intervención en la realidad educativa. Revista Bibliográfica de Geografía y Ciencias Sociales, 207, 1. http://www.ub.edu/ geocrit/b3w-207.htm

García, F. J. (2014). El proceso de enseñar y aprender. Modelos didácticos. En I. Gómez y F. J. García (Eds.), Manual de Didáctica. Aprender a enseñar (pp. 25-44). Madrid: Pirámide.

García, R., y Parra, J. M. (2010). Didáctica e innovación curricular. Madrid: Los Libros de la Catarata.

Gimeno, J. (1981). Teoría de la enseñanza y desarrollo del currículo. Madrid: Anaya.

Gimeno, P. (1995). Teoría Crítica de la Educación. Madrid: UNED.

Gimeno, P. (2013). Reflexiones críticas y autocríticas sobre Pedagogía Crítica. Revista Interuniversitaria de Formación del Profesorado, 77, 77-92. https://dialnet.unirioja.es/servlet/articulo?codigo=4840079

Gloag, K. (2015). «A Thing of the Past»: Canon Formation and the Postmodern Condition. En V. Kurkela y M. Mantere (Eds.), Critical Music Historiography: Probing Canons, Ideologies and Institutions (pp. 227-237). Surrey: Ashgate.

Goehr, L. (1994). The imaginary museum of musical works. New York: Oxford University Press.

Goehr, L. (2002). In the shadow of the Canon. Musical Quarterly, 86(2), 307-328. https://doi.org/10.1093/ musqtl/gdg012

Gould, E., Countryman, J., Morton, C., y Rose, L. S. (Eds.). (2009). Exploring Social Justice. How Music Education Might Matter. Toronto: Canadian Music Educators' Association.

Gowan, J. (2016). A Polysemy of Meanings : Music Education for Critical Pedagogy. Canadian Music Educator, 57(3), 23-28. https://www.questia.com/magazine/1P3-4140662951/a-polysemy-ofmeanings-music-education-for-critical

Guba, E. G., y Lincoln, Y. S. (1994). Competing Paradigms in Qualitative Research. En N. Denzin y Y. Lincoln (Eds.), Handbook of Qualitative Research (pp. 105-117). Thousand Oaks: SAGE.

Hebert, D. G. (2009). Musicianship, Musical Identity, and Meaning as Embodied Practice. En T. Regelski y T. Gates (Eds.), Music Education for Changing Times (pp. 39-55). Londres: Springer.

Heinich, R. (1975). Tecnología y administración de la enseñanza. México D.F.: Trillas.

Helm, E. E. (1994). The canon and the curricula. A Study of Musicology and Ethnomusicology Programs in America. Stuyvesant: Pendragon Press.

Hernández, C., y Guárate, A. Y. (2017). Modelos didácticos pra situaciones y contextos de aprendizaje. Madrid: Narcea.

Herrán, A. D. La. (2005). Reflejo de los paradigmas consensuados en el conocimiento pedagógico. En A. de la Herrán, E. Machado y E. Edmundo (Eds.), Investigar en educación: fundamentos, aplicación y nuevas perspectivas (pp. 35-78). Madrid: Dilex.

Hess, J. (2015). Decolonizing music education: Moving beyond tokenism. International Journal of Music Education, 33(3), 336-347. https://doi.org/10.1177/0255761415581283 


\section{EST U D O S Y E N SAYOS}

Ho, W. C. (2006). The Politics of Implementing Local Cultures in Music Education in Taiwan. Research and Issues in Music Education, 4(1), 1-14. https://commons.lib.jmu.edu/rime/vol4/iss1/4/

Ho, W. C. (2009). Social developments and school music education: The struggles in Hong Kong. Discourse: Studies in the Cultural Politics of Education, 30(2), 179-193. https://doi. org/10.1080/01596300902809203

Ho, W. C. (2015). Challenges to Values Education in School Music Education between Nationalism and Multiculturalism in Beijing, China. En E. Burgess (Ed.), Music Education and Perceptions (pp. 167174). Nueva York: Nova Science Publishers.

Ishii, Y. (2018). The roles played by a common language and music education in modernization an nationstate building in Asia. Espacio, Tiempo y Educación, 5(2), 55-76. https://doi.org/10.14516/ete.221

Johnson, R. (2009). Critically Reflective Musicianship. En T. Regelski y T. Gates (Eds.), Music Education for Changing Times (pp. 17-26). Nueva York: Springer.

Jorquera, M. C. (2010). Modelos didácticos en la enseñanza musica: el caso de la escuela española. Revista Musical Chilena, 241, 52-74. https://revistamusicalchilena.uchile.cl/index.php/RMCH/article/ view/10571

Kant, I. (2007). Critique of judgement. Oxford: Oxford University Press.

Kennedy, K. (2016). Singing about soldiers in German schools, from 1890 to 1945. Paedagogica Historica, 52(1-2), 76-91. https://doi.org/10.1080/00309230.2016.1139602

Knuuttila, T. (2005). Models as Epistemic Artefacts: Towards a Non.Representationalist Account of Scientific Representation. Helsinki: Department of Philosophy. University of Helsinki.

Koza, J. E. (2009). Listening for Whiteness: Hearing Racial Politics in Undergraduate School Music. En T. Regelski y T. Gates (Eds.), Music Education for Changing Times (pp. 85-95). Londres: Springer.

Kuhn, T. (1975). La estructura de las revoluciones cientificas. México D.F.: Fondo de Cultura Económica.

Lee, A. (2006). The influence of governmental control and early Christian missionaries on music education of Aborigines in Taiwan. British Journal of Music Education, 23(2), 205-216. https://doi. org/10.1017/s0265051706006930

Lincoln, Y. S., y Guba, E. G. (1984). Naturalistic inquiry. California: SAGE Publications.

Lind, V. R., y McKoy, C. L. (2016). Culturally Responsive Teaching in Music Education. New York: Routledge.

Lorenzo, M. (1986). Enfoque sistémico de la enseñanza. En Ó. Sáenz (Ed.), Didáctica General (pp. 23-40). Madrid: Ediciones Anaya.

Lorenzo, N., y Pla, M. (2001). Teoría de la enseñanza: modelos aplicados al proceso de enseñanzaaprendizaje. En F. Sepúlveda y N. Rajadell (Eds.), Didáctica general para psicopedagogos (pp. 58-100). Madrid: Universidad Nacional de Educación a Distancia.

Marín, L. (2011). The Notion of Paradigm. Redalyc, XXVI, 34-45. https://www.redalyc.org/articulo. oa?id=86005004

Mayo, P. (2008). La praxi alliberadora. El llegat de Paulo Freire per a l'educació radical i alliberadora. Xàtiva: Edicions del Crec i Denes Editorial.

Medina, A. (2002). Enfoques, teorías y modelos de la Didáctica. En Didáctica General. Madrid: Pearson Educación. 
Nayive, L., y León, A. (2005). Perspectiva crítica de Paulo Freire y su contribución a la teoría del currículo. Educere: Artículos aritrados, 29, 159-164. http://erevistas.saber.ula.ve/index.php/educere/article/ view/11917

Nettl, B. (2015). The Study of Ethnomusicology. Urbana: University of Illinois Press.

O’Neill, S. A. (2015). Youth Empowerment and Transformative Music Engagement. En C. Benedict, P. Schmidt, G. Spruce, y P. Woodford (Eds.), The Oxford Handbook of Social Justice in Music Education (pp. 388-405). Nueva York: Oxford University Press.

Pérez, M. G. (1990). Investigación-acción. Aplicaciones al campo social y educativo. Madrid: Dykinson.

Pettan, S. (2015). Applied Ethnomusicology in the Global Arena. En S. Pettan y J. T. Titon (Eds.), The Oxford Handbook of Applied Ethnomusicology (pp. 29-53). Nueva York: Oxford University Press.

Pont, E. (2002). Models d'acció didàctica. Barcelona: Universitat Oberta de Catalunya.

Popkewitz, T. (1980). Paradigms in Educational Science: Different Meaning and Purpose to Theory. The Journal of Education, 162(1), 28-46. https://doi.org/10.1177/002205748016200104

Popkewitz, T. (1988). Paradigma e ideología en inevstigación educativa. Madrid: Mondadori.

Portides, D. (2008). Models. En S. Psillos y M. Curd (Eds.), TheRoutledge Companion to Philosophy of Science (pp. 385-395). Abingdon: Routledge.

Reigeluth, C. M. (2000). ¿En qué consiste la teoría de diseño educativo y cómo se está transformando? En C. M. Reigeluth (Ed.), Diseño de la instrucción. Teorías y modelos. Un nuevo paradigma de la teoría de la instrucción (pp. 15-40). Madrid: Aula XXI/Santillana.

Rice, T. (2013). Ethnomusicology. A very short introduction. Nueva York: Oxford University Press.

Rodríguez, C. (2002). Prontuario de musicología. Barcelona: Clivis.

Rodríguez, M. (1997). Hacia una didáctica crítica. Madrid: La Muralla.

Rodríguez, M. (2002a). Currículo y teorías curriculares. En M. Rodríguez (Ed.), Didáctica general. Quéy cómo enseñar en la sociedad de la información, (pp. 99-140). Madrid: Biblioteca Nueva.

Rodríguez, M. (2002b). Modelos de diseño curricular para elaborar proyectos didácticos. En M. Rodríguez (Ed.), Didáctica general. Qué y cómo enseñar en la sociedad de la información (pp. 141-187). Madrid: Biblioteca Nueva.

Rubio, J. (1984). Positivismo, hermenéutica y teoria crítica en las ciencias sociales. Barcelona: Humanitas.

Sabariego, M. (2004). La investigación educativa: génesis, evolución y características. En R. Bisquerra (Ed.), Metodología de la investigación educativa (pp. 51-87). Madrid: La Muralla.

Sáez, J. (1989). La construcción de la educación. Murcia: ICE Universidad de Murcia.

Samson, J. (2001a). Canon. En D. Root (Ed.), Grove Music Online (pp. 1-3). Oxford: Oxford University Press.

Samson, J. (2001b). The great composer. En J. Samson (Ed.), The Cambridge History of Nineteenth-Century Music (pp. 259-284). Cambridge: Cambridge University Press.

Sánchez-Santamaría, J. (2013). Paradigmas de la investigación educativa: De las leyes subyacentes a la modernidad reflexiva. Entelequia, revista interdisciplinar, 16(2013), 91-99. http://www.eumed.net/ entelequia/pdf/2013/e16a06.pdf 


\section{ESTUDIOS Y E N SAYOS}

Sanjosé, V. (1994). Hacia una didáctica de la educación musical científicamente fundamentada. Música y educación: Revista trimestral de pedagogía musical, 7(2), 17-34.

Shaw, J. (2012). The Skin that We Sing. Music Educators Journal, 98(4), 75-81. https://doi. org/10.1177/0027432112443561

Tadeu, T. (2001). Espacios de identidad. Barcelona: Octaedro.

Talbot, M. (2002). The musical work. Teality or invention? New York: Cambridge University Press.

Thompson, J. D. (2015). Towards cultural responsiveness in music instruction with black detained youth: An analytic autoethnography. Music Education Research, 17(4), 421-436. https://doi.org/10.1080/1461 $\underline{3808.2014 .930117}$

Vaugeois, L. C. (2009). Music Education as a Practice of Social Justice. En E. Gould, J. Countryman, C. Morton, y L. S. Rose (Eds.), Exploring Social Justice. How Music Education Might Matter (pp. 2-22). Toronto: Canadian Music Educators' Association.

Weber, W. (1992). The Rise of Musicl Classics in Eighteenth-Century England. A Study in Canon, Ritual, and Ideology. Oxford: Clarendon Press.

Wiens, K. F. (2015). Considering Culturally Responsive Teaching, Children, and Place in the Music Room. General Music Today, 29(1), 19-23. https://doi.org/10.1177/1048371315594005

Wolff, J. (1996). The ideology of autonomous art. En R. Leppert y S. McClary (Eds.), Music and Society. The Politics of Composition, Performance and Reception. New York: Cambridge University Press.

Younker, B. A., y Hickey, M. (2007). Examining the profession through the lens of social justice: two music educators' stories and their stark realizations. Music Education Research, 9(2), 215-227. https:// doi.org/10.1080/14613800701384334 